\title{
Abuse and misuse of antidepressants
}

This article was published in the following Dove Press journal:

Substance Abuse and Rehabilitation

14 August 2014

Number of times this article has been viewed

\author{
Elizabeth A Evans \\ Maria A Sullivan \\ Department of Psychiatry, Columbia \\ University College of Physicians and \\ Surgeons, New York, NY, USA
}

Background: Rates of prescription drug abuse have reached epidemic proportions. Large-scale epidemiologic surveys of this under-recognized clinical problem have not included antidepressants despite their contribution to morbidity and mortality. The purpose of this review is to look specifically at the misuse of antidepressants and how this behavior may fit into the growing crisis of nonmedical use of prescription drugs.

Methods: We conducted a comprehensive search on PubMed, Medline, and PsycINFO using the search terms "antidepressant", "abuse", "misuse", "nonmedical use", "dependence", and "addiction", as well as individual antidepressant classes (eg, "SSRI") and individual antidepressants (eg, "fluoxetine") in various combinations, to identify articles of antidepressant misuse and abuse.

Results: A small but growing literature on the misuse and abuse of antidepressants consists largely of case reports. Most cases of antidepressant abuse have occurred in individuals with comorbid substance use and mood disorders. The most commonly reported motivation for abuse is to achieve a psychostimulant-like effect. Antidepressants are abused at high doses and via a variety of routes of administration (eg, intranasal, intravenous). Negative consequences vary based upon antidepressant class and pharmacology, but these have included seizures, confusion, and psychotic-like symptoms.

Conclusion: The majority of individuals prescribed antidepressants do not misuse the medication. However, certain classes of antidepressants do carry abuse potential. Vulnerable patient populations include those with a history of substance abuse and those in controlled environments. Warning signs include the presence of aberrant behaviors. Physicians should include antidepressants when screening for risky prescription medication use. When antidepressant misuse is detected, a thoughtful treatment plan, including referral to an addiction specialist, should be developed and implemented.

Keywords: antidepressant, prescription, misuse, abuse, nonmedical use, dependence, addiction

\section{Introduction}

While prescription drugs have been used effectively and appropriately to treat both medical and psychiatric illness in the vast majority of patients, rates of prescription abuse have escalated and have reached epidemic proportions. ${ }^{1}$ Despite the growing concern regarding misuse and abuse of prescription drugs, much of the earlier epidemiologic data were limited, in part, due to ambiguous definitions of terms such as "abuse", "misuse", and "nonmedical use."2,3 These terms are often used interchangeably to describe a variety of behaviors and motives not intended by the prescribing physician. ${ }^{3}$ More recent large-scale surveys, including the National Epidemiologic
Correspondence: Maria A Sullivan Department of Psychiatry, Columbia University College of Physicians and Surgeons, I05I Riverside DR. Unit I20, New York, NY, 10032, USA

Email mas23@columbia.edu 
Survey on Alcohol and Related Conditions (NESARC) and the National Survey on Drug Use and Health (NSDUH), define these terms more precisely. The NSDUH defines nonmedical use as "use of at least one of these medications (sedatives, tranquilizers, opioids, stimulants) without a prescription belonging to the respondent, or use that occurred simply for the experience or feeling the drug caused". 4 NESARC utilizes a similar definition: "use without a prescription, in greater amounts, more often, or longer than a doctor said you should use them". ${ }^{2}$ Both surveys employ the terms "abuse" and "dependence" based upon DSM-IV (Diagnostic and Statistical Manual of Mental Disorders, Fourth Edition) criteria. ${ }^{2,4}$

In 2012, according to the NSDUH, there were approximately 2.4 million persons aged 12 years or older who used psychotherapeutics (sedatives, tranquilizers, opioids, stimulants) nonmedically for the first time within the past year, which averages to about 6,700 initiates per day. ${ }^{4}$ Further, nonmedical use of psychotherapeutics is second only to marijuana in terms of the illicit drug with the highest levels of past-year dependence or abuse. ${ }^{4}$ According to NESARC, lifetime prevalences of nonmedical use of sedatives, tranquilizers, opioids, and amphetamines in 2001-2002 were $4.1 \%, 3.4 \%, 4.7 \%$, and $4.7 \%$, respectively. ${ }^{2}$ Corresponding rates of abuse and/or dependence were $1.1 \%$, $1.0 \%, 1.4 \%$, and $2.0 \%{ }^{2}$

The reasons for nonmedical use of prescription drugs are complex. However, increased availability of prescription drugs has likely contributed. ${ }^{3,5,6}$ In the NSDUH, past-year users of psychotherapeutic drugs are asked how they obtained the drugs they most recently used nonmedically. More than half of the nonmedical users of pain relievers, tranquilizers, stimulants, and sedatives aged 12 years or older obtained the prescription drugs used "from a friend or relative for free" ${ }^{4}$ About four in five of these nonmedical users indicated that their friend or relative had obtained the drugs from a single doctor. ${ }^{4}$

Another trend leading to increased access is the use of the Internet and what are termed "no-prescription websites", which first came to the attention of law enforcement authorities in the mid-1990s. These websites offer to sell controlled substances to customers without regard for federal or local laws, without a valid prescription, and without medical guidance or supervision. ${ }^{7}$ The National Center on Addiction and Substance Abuse at Columbia University reported an increase in the number of websites selling controlled prescription drugs from 154 in 2004 to 187 in 2007, and a total of 581 sites in 2007 either advertising or selling controlled substances. ${ }^{8}$
In addition to access, perceptions of the nonmedical use or abuse of prescription drugs as being more socially acceptable, less stigmatized, and safer than illicit substances may be contributing to increased rates of misuse. ${ }^{3}$ A webbased survey of approximately 3,600 undergraduate students conducted in 2005 that asked students about their use and perceptions of peers' use of nonmedical prescription drugs found that the majority of students overestimated the prevalence of this practice. ${ }^{9}$ Data from the Monitoring the Future Survey, a large and ongoing survey of adolescents and young adults, suggests that in 2013, 12th graders perceived the harmfulness of prescription medications to be less than that of pharmacologically similar illicit substances. ${ }^{10}$ For instance, $39 \%$ of 12 th graders felt regular nonmedical use of Adderall ${ }^{\circledR}$ (Shire, Wayne, PA, USA) was potentially harmful, whereas $72 \%$ believed that use of crystal methamphetamine once or twice was harmful; $78 \%$ felt occasional use of heroin was potentially risky versus only $57 \%$ who felt there was risk of harm with occasional use of prescription opioids. ${ }^{10}$ The Partnership Attitude Tracking Study found that $27 \%$ of teens believe that misusing and abusing prescription drugs is safer than using "street drugs", and one third believe "it's okay to use prescription drugs that were not prescribed to them to deal with an injury, illness or physical pain". ${ }^{11}$ Certain prescription medications are not detected in standard drug screens, and this may also influence their perceived attractiveness to individuals using them nonmedically.

Despite the perception by some that the nonmedical use of prescription medications is safer than that of illicit drugs, there are a number of potential adverse consequences. The Drug Abuse Warning Network, which collects data from 355 nonfederal US hospitals that have 24-hour emergency departments, estimated that in 2011, 1,244,872 emergency department visits involved nonmedical use of prescription medications or over-the-counter medications. ${ }^{12}$ The majority of these visits involved opioids $(488,004)$, followed by anxiolytics, sedatives, and hypnotics $(421,940)$, and antidepressants $(88,965)$ (samhsa.gov). The Drug Abuse Warning Network estimated that in 2011 there were 228,366 emergency department visits resulting from a drug-related suicide attempt, almost all (95\%) involving prescription drugs or over-the-counter medications. ${ }^{12}$ Most of the emergency department visits involved anxiolytics, sedatives, and hypnotics (41\%) followed by antidepressants (20\%) and opioids (14\%). ${ }^{12}$ Deaths from drug overdose have also increased over the past decade. ${ }^{13}$ In 2010, there were 38,329 drug overdose deaths in the USA, most involving pharmaceuticals. ${ }^{14}$ Of the pharmaceutical-related overdose 
deaths, 16,451 (74.3\%) were unintentional, 3,780 (17.1\%) were suicides, and $1,868(8.4 \%)$ were of undetermined intent. ${ }^{14}$ Opioids $(16,651,75.2 \%)$, benzodiazepines $(6,497,29.4 \%)$, antidepressants $(3,889,17.6 \%)$, and antiepileptic and antiparkinsonism drugs $(1,717,7.8 \%)$ were the pharmaceuticals (alone or in combination with other drugs) most commonly involved in pharmaceutical overdose deaths. ${ }^{14}$

While the majority of those using prescription drugs nonmedically do not develop DSM-IV abuse or dependence, in 2011 more than 2.1 million individuals met past-year criteria for abuse or dependence of psychotherapeutics. ${ }^{4}$ Furthermore, using data from the NESARC, McCabe et al found that earlyonset nonmedical use of prescription drugs was a significant predictor of lifetime development of prescription drug abuse or dependence. ${ }^{15}$ In addition to mortality and morbidity, there is a large monetary burden to society of nonmedical use of prescription drugs through loss of workplace productivity, health care, and criminal justice costs. ${ }^{16,17}$ To our knowledge, there are no published data looking at the cost of nonmedical use of antidepressants in particular or all prescription drugs in general, but societal costs of nonmedical use of prescription opioids were estimated to be $\$ 53$ billion in 2006 and 56 billion dollars in 2007..$^{16,17}$

While antidepressants as a class are not included specifically in the aforementioned epidemiologic studies, they do contribute to morbidity as noted in the Drug Abuse Warning Network data, and are also subject to nonmedical use and abuse. The category of "antidepressants" encompasses medications with a variety of pharmacologic properties (eg, anxiolytic, sedating, stimulating), some of which may make them attractive candidate drugs for misuse. Further, individuals with mood disorders (ie, those prescribed antidepressants) often have comorbid substance use disorders, and thus may be vulnerable to misuse or abuse of medications. In the NESARC sample, among those with a lifetime major depressive disorder, $40.3 \%$ had an alcohol use disorder (abuse or dependence) and 17.2\% had a drug use disorder (abuse or dependence). ${ }^{18}$ Comorbidity is even higher with bipolar disorder and substance use disorders. In the National Comorbidity Survey Replication, the lifetime prevalence rate of DSM-IV bipolar I disorder and any substance use disorder was $60.3 \%$, with alcohol abuse being the most prominent at $56.3 \%{ }^{19}$

The purpose of this review is to examine specifically the misuse of antidepressants and how this behavior fits into the growing crisis of nonmedical use of prescription drugs. We will discuss the epidemiology of antidepressant misuse, consider antidepressant pharmacology, and describe symptoms of addiction and misuse. We will offer recommendations for treatment as well as suggest directions for further research aimed at identifying and treating this underrecognized clinical phenomenon.

\section{Methods}

We conducted a comprehensive search on PubMed, Medline, and PsycINFO of articles published before April 2014. We used the search terms "antidepressant", "abuse", "misuse", "nonmedical use", "dependence", and "addiction", as well as individual antidepressant classes (eg, "SSRI") and individual antidepressants (eg, "fluoxetine") in various combinations in order to summarize relevant data concerning misuse and abuse of antidepressant medications. Given the paucity of relevant articles, case reports were included. Titles and abstracts were evaluated for topic relevance, and additional articles were identified from the reference lists of those articles deemed relevant. A total of 68 articles, largely case reports/series, were included. Five articles with titles suggestive of amineptine misuse were excluded as they were not published in English and we were unable to access the articles for translation.

\section{Scope of antidepressant misuse and pharmacology}

Since most large-scale epidemiologic surveys have not included antidepressant misuse as a category of substance abuse that is specifically measured, it is difficult to fully characterize the prevalence of antidepressant misuse. However, there is a growing, albeit relatively small, literature reporting misuse and abuse of antidepressants. To give a sense of the limited scope of the current literature, the most frequently cited misused class of antidepressants is that of the monoamine oxidase inhibitors (MAOIs). Our literature search of MAOI abuse and misuse resulted in a total of 18 articles, 15 case report/case series, ${ }^{20-34}$ and three review articles. ${ }^{35-37}$ The majority of the cases of MAOI misuse were reported in the 1960s to 1990s. In the last decade, the most commonly cited misused antidepressant is bupropion. Our literature search of bupropion abuse and misuse yielded a total of 13 articles, two review articles, ${ }^{38,39}$ and a number of case reports..$^{40-50}$

\section{Bupropion}

Bupropion acts via dual inhibition of norepinephrine and dopamine reuptake, thus increasing the intrasynaptic concentrations of these neurotransmitters. ${ }^{51}$ 
Bupropion sustained-release has been shown to have activity in the nucleus accumbens, a key component of the brain reward systems implicated in the development of addiction..$^{51,52}$ Theoretically, given its noradrenergic and dopaminergic effects, bupropion may promote regulation of function in mesolimbic brain circuits, an important system in the activating and reinforcing effects of indirect sympathomimetics (eg, cocaine, methamphetamine, nicotine). ${ }^{53,54}$ Bupropion is approved by the US Food and Drug Administration (FDA) for treatment of major depressive disorder, seasonal affective disorder, and nicotine addiction, and is often used "off label" for attention deficit/hyperactivity disorder, bipolar depression, sexual dysfunction, and obesity. ${ }^{55,56}$ While bupropion is generally considered to be a drug of low abuse potential, ${ }^{51}$ there is evidence that bupropion is abused, particularly in correctional facilities. ${ }^{38-40}$ According to Hiliard et al, the decreased availability of stimulants and benzodiazepines in correctional facilities has led inmates to seek alternative replacements, and bupropion has become a replacement for some. ${ }^{39,46}$ As a result, some correctional facilities have responded by removing bupropion from their pharmacy formularies. ${ }^{40}$

Case reports describe stimulant and cocaine-like, euphoric effects, or a sensation of feeling "high" by those abusing bupropion. ${ }^{40-44}$ There are also anecdotal reports of antidepressants, including bupropion, being used by athletes in an attempt to stimulate their motivation and obtain a euphoric effect. ${ }^{57}$ The extent of antidepressant use for this purpose is unknown; however, until 2003, bupropion was on the World Anti-Doping Agency list of prohibited substances. ${ }^{57}$ While bupropion is not currently prohibited by the World Anti-Doping Agency, it remains on the 2014 monitoring list (ie, subject to monitoring). ${ }^{58}$

While understanding the pharmacology of bupropion offers insight into why it can be misused, the route of administration is also an important factor in abuse potential. Occasional case reports cite the oral use of bupropion to get "high", ${ }^{44}$ but the majority of cases in the literature involve intranasal administration. The nasopharynx is a highly vascularized surface area for systemic drug absorption directly into the blood stream, and thus bypassing breakdown by the gastrointestinal tract and first-pass metabolism in the liver. Animal data suggest extensive metabolism on first-pass effect with bupropion, with bioavailability of $5 \%-20 \%{ }^{43}$ While the pharmacokinetics of bupropion have only been described with oral administration, ${ }^{46}$ crushing and snorting the drug allows for higher and more rapid rise in plasma concentrations, which can induce euphoria. Intravenous administration or smoking allow for even more rapid concentrations. Baribeau and Araki published the only case report of intravenous bupropion abuse, ${ }^{43}$ they describe a 29 -year-old woman who was dissolving $300 \mathrm{mg}$ tablets in water and injecting 1,200 mg daily (maximum oral dose recommended by the FDA is 450 $\mathrm{mg}){ }^{43}$ She described a euphoric and stimulant-like effect from the intravenous bupropion, and reported irritability and low mood during periods of abstinence. ${ }^{43}$

Potential consequences of bupropion abuse and misuse have not been studied. However, bupropion is known to have a dose-dependent increased risk of seizures that is also higher with immediate-release as compared with sustained-release. ${ }^{59}$ Thus, misuse of high doses, or by routes that allow for much greater, more rapid bioavailability and higher peak plasma levels, would pose an increased seizure risk. Concurrent use of alcohol, stimulants, or cocaine also enhances the risk of seizures in those using bupropion. ${ }^{59}$ Kim and Steinhart reported a case of what was thought to be intranasal bupropion-induced seizures. ${ }^{46}$ Psychotic symptoms at therapeutic doses have been described in case reports, particularly in older adults with complicating factors. ${ }^{56}$ In one case, a 49-year-old incarcerated man, with no history of psychotic illness, experienced auditory hallucinations after snorting up to 1,200 mg of bupropion daily. ${ }^{40}$ The auditory hallucinations resolved after he was denied access to bupropion. ${ }^{40}$ High-dose bupropion may also be cardiotoxic ${ }^{60}$ (see Table 1).

\section{Monoamine oxidase inhibitors}

MAOIs were first identified as effective antidepressants in the late $1950 \mathrm{~s} .{ }^{61}$ They act by inhibiting the activity of the isoenzymes monoamine oxidase- $\mathrm{A}$ and monoamine oxidase-B (MAO-A and MAO-B, respectively), preventing the breakdown of monoamine neurotransmitters and thereby increasing their availability. ${ }^{61}$ The main substrates for MAO-A are epinephrine, norepinephrine, and serotonin. ${ }^{61}$ The main substrates for MAO-B are phenylethanolamine, tyramine, and benzylamine. ${ }^{61}$ Dopamine is metabolized by both isoenzymes. ${ }^{61}$ Some MAOIs are selective for either $\mathrm{MAO}-\mathrm{A}$ or MAO-B, and some are nonselective (ie, they inhibit both MAO-A and MAO-B).

Like other antidepressants, MAOIs are generally considered not to have abuse potential, but there are a number of case reports/series of MAOI misuse. ${ }^{20-37}$ While the route of administration for the misused MAOI was not specified in all of the case reports, it was implied to be orally in all cases. Phenelzine and tranylcypromine, both nonselective MAOIs, are most cited in the literature. The mechanism 
Table I Abused and misused antidepressants: effects and adverse effects

\begin{tabular}{|c|c|c|c|}
\hline Drug/drug class & Route of administration & Reported drug effect & Potential adverse effects \\
\hline Bupropion & $\begin{array}{l}\text { Intranasal }>\text { oral }> \\
\text { intravenous }\end{array}$ & $\begin{array}{l}\text { Stimulant-like effects including } \\
\text { euphoria and enhanced } \\
\text { motivation; "high" }\end{array}$ & $\begin{array}{l}\text { Seizure, psychotic symptoms, } \\
\text { cardiotoxicity; withdrawal/ } \\
\text { discontinuation phenomena }\end{array}$ \\
\hline $\begin{array}{l}\text { Monoamine oxidase } \\
\text { inhibitors }\end{array}$ & Oral & Stimulant-like effects & $\begin{array}{l}\text { Hypertensive crisis, delirium, } \\
\text { thrombocytopenia; withdrawal/ } \\
\text { discontinuation phenomena }\end{array}$ \\
\hline Tricyclic antidepressants & Oral & $\begin{array}{l}\text { Euphoria, "high", more sociable; } \\
\text { dissociative effects including: } \\
\text { distorted sense of time and } \\
\text { "numbness" }\end{array}$ & $\begin{array}{l}\text { Confusion, delirium, seizure, } \\
\text { orthostatic hypotension, cardiac } \\
\text { conduction disorder, cardiac } \\
\text { arrhythmia; withdrawal/ } \\
\text { discontinuation phenomena }\end{array}$ \\
\hline $\begin{array}{l}\text { Serotonin and } \\
\text { norepinephrine } \\
\text { reuptake inhibitors }\end{array}$ & $\begin{array}{l}\text { Oral (one case involved } \\
\text { crushing pills and ingesting oral) }\end{array}$ & $\begin{array}{l}\text { Stimulant-like effects, more } \\
\text { empathic and sociable, euphoria }\end{array}$ & $\begin{array}{l}\text { Hypertensive crisis, weight loss, } \\
\text { tremor; withdrawal/discontinuation } \\
\text { phenomena }\end{array}$ \\
\hline $\begin{array}{l}\text { Selective serotonin } \\
\text { reuptake inhibitors }\end{array}$ & $\begin{array}{l}\text { Oral (one case involved } \\
\text { opening tablets and ingesting } \\
\text { contents oral) }>>\text { intravenous }\end{array}$ & Stimulant-like effects & $\begin{array}{l}\text { Appetite suppression, serotonin } \\
\text { syndrome, seizure; withdrawal/ } \\
\text { discontinuation phenomena }\end{array}$ \\
\hline Tianeptine & Oral $>>$ intra-arterial & Stimulant-like effects & $\begin{array}{l}\text { Appetite suppression; withdrawal/ } \\
\text { discontinuation phenomena }\end{array}$ \\
\hline Amineptine & Oral & Stimulant-like effects & $\begin{array}{l}\text { Tachycardia, decreased appetite and } \\
\text { weight loss, irritability, insomnia, } \\
\text { hepatotoxicity }\end{array}$ \\
\hline
\end{tabular}

Note: No published cases of abuse/misuse were found of serotonin 2 (5-HT2) receptor antagonists (eg, trazodone, nefazodone) or alpha-2 adrenergic receptor antagonists (eg, mirtazapine).

of abuse may be associated with the similarity in chemical structure to amphetamine; however, the mechanism of action is different, and thus the pharmacologic basis for potential abuse is unknown. ${ }^{24} \mathrm{~A}$ risk of hypertensive crisis exists when nonselective MAOIs are combined with certain foods that are high in tyramine, and this risk is highest for tranylcypromine.$^{61}$ Thus, those using high doses of MAOIs, or individuals not aware of the recommended diet restrictions, are more at risk. Delirium and thrombocytopenia have been reported in a number of cases of overdose and withdrawal of tranylcypromine, and may be more pronounced if high doses are used. ${ }^{21,23,24,35,62,63}$

\section{Tricyclic antidepressants}

Tricyclic antidepressants (TCAs) were the first class of antidepressants to be widely used in depression. ${ }^{64}$ The TCAs act primarily as serotonin-norepinephrine reuptake inhibitors. Tertiary TCAs are more potent in blocking the serotonin transporter, whereas the secondary TCAs are relatively selective in blocking the norepinephrine transporter. ${ }^{64}$ The TCAs also block muscarinic receptors (producing anticholinergic effects), histamine receptors, and alpha-1 and alpha-2 receptors. ${ }^{64}$
The first cases of TCA misuse were reported in the 1970s. ${ }^{65,66}$ Cohen et al surveyed 346 individuals enrolled in a methadone maintenance program, and found that $25 \%$ reported taking amitriptyline with the purpose of achieving euphoria. ${ }^{65}$ Many additional case reports of TCA misuse have followed. ${ }^{67-75}$ In the 14 cases described by Shenouda and Desan, all but one individual had a comorbid substance dependence diagnosis, and the tricyclic drug misused in all cases was a tertiary TCA, with amitriptyline being the most commonly abused. ${ }^{75}$ The majority of the case reports do not specify the route of administration by which TCAs are misused. However, those that do specify, report the medications were taken orally. In unspecified cases, the authors implied that the TCAs were misused orally by defining the use as taking escalating doses of the prescribed medication. Anecdotally, individuals misusing TCAs have reported taking large doses to produce a "high", euphoria, and a "pleasant" feeling. ${ }^{75}$ While the extent of TCA misuse and abuse is unknown, reports of TCA abuse have also been reported in prison populations. Similar to the policies for bupropion, TCAs have been removed from formularies in some correctional facilities. ${ }^{40,45}$

While the pharmacologic basis for TCA abuse is unknown, it is interesting to note that nearly all of the case 
reports involve abuse of a tertiary TCA. ${ }^{65-70,72-75}$ The more prominent anticholinergic and antihistaminergic effects ${ }^{76}$ of tertiary TCAs may be contributing to their abuse liability. The anticholinergic and antihistaminergic effects of TCAs can produce confusion and delirium, which are potential consequences of misuse of these medications. ${ }^{64}$ Seizures are also a potential dose-dependent consequence. ${ }^{64}$ Orthostatic hypotension and falls may occur in those using and misusing TCAs. Most concerning is the effect of TCAs on cardiac conduction. ${ }^{64}$ TCAs can be lethal in overdose, and cardiac arrhythmia is the principal cause of death in overdose. ${ }^{64}$

\section{Serotonin and norepinephrine reuptake inhibitors}

Serotonin and norepinephrine reuptake inhibitors (SNRIs) include venlafaxine, desvenlafaxine, and duloxetine. While TCAs also inhibit serotonin and norepinephrine, the selectivity of the SNRIs for these two reuptake transporters distinguishes the two classes. ${ }^{77}$ We found two case reports in the literature of venlafaxine abuse. ${ }^{78,79}$ One case was of a 38 -year-old man with a history of depression and amphetamine dependence who was crushing and orally ingesting doses up to 4,050 mg (maximum dose recommended by the FDA is $375 \mathrm{mg}$ ) for the purpose of achieving an "amphetamine-like high". ${ }^{79}$ The second case was of a 53-year-old man, also with a history of substance abuse, using up to $3,750 \mathrm{mg} /$ day of oral venlafaxine for the purposes of feeling "more empathic and sociable" and "elated" mood. ${ }^{78}$ The first case presented to medical attention with chest pain, presumably related to high-dose venlafaxine, and the second case presented for venlafaxine detoxification with profound weight loss, tremor, dizziness, and muscle weakness. ${ }^{78,79}$ At therapeutic doses, venlafaxine will cause sustained increases in blood pressure in some individuals, and thus in practice it is recommended to check blood pressure regularly; ${ }^{77}$ higher doses likely place someone at greater risk of hypertension and hypertensive crisis. At recommended doses, SNRIs do not affect cardiac conduction or lower seizure threshold; however, in overdose they may do both. ${ }^{77,80}$ Many of the post-marketing fatal overdoses involved combinations of venlafaxine and other drugs and/or alcohol. ${ }^{81-84}$ These cases highlight the heightened risk of antidepressant abuse among individuals with a history of illicit drug abuse. They also demonstrate that the motivation for abusing an SNRI may be either to achieve an amphetamine-like effect or to experience the dissociative effects of excess serotonin.

\section{Selective serotonin reuptake inhibitors}

The selective serotonin reuptake inhibitors (SSRIs) are the most commonly prescribed antidepressants, and are considered first-line in treatment for major depressive disorder and for most anxiety disorders. ${ }^{59}$ The SSRIs selectively block the reuptake of serotonin. However, it is important to recall that while they are more selective at the serotonin receptor, all the SSRIs impact other neurotransmitter systems, including norepinephrine and dopamine reuptake blockade. ${ }^{59}$ Despite the popularity in prescribing, there are relatively few cases in the literature of abuse or misuse of SSRIs. We found a total of six articles, describing seven cases, all involving fluoxetine. ${ }^{85-90}$ In all but one of the cases, ${ }^{87}$ the route of abuse was either stated as orally, or implied to be orally by the authors. Wilcox described a case of a woman with anorexia nervosa taking up to $120 \mathrm{mg}$ /day of fluoxetine for appetite suppression and weight loss. ${ }^{86}$ Another case of oral fluoxetine abuse involved a woman with a history of dysthymia and polysubstance abuse who would misuse fluoxetine by opening the tablets and "sucking" very low doses (1 mg) through her mouth, reporting stimulant-like effects. ${ }^{90}$ Paligaro and Paligaro reported a case of intravenous fluoxetine abuse by a patient with a mood disorder and a history of intravenous heroin and cocaine abuse. ${ }^{87}$ Tinsley et al and Menecier et al described cases of DSM-III-R (Diagnostic and Statistical Manual of Mental Disorders, Third Edition Revised) and DSM-IV fluoxetine dependence in individuals with histories of polysubstance use. ${ }^{88,89}$ Taieb et al reported a case of a patient with a history of amineptine abuse, depression, and borderline personality disorder, who presented with seizure and symptoms of serotonin syndrome. ${ }^{85}$ The patient was using up to $840 \mathrm{mg}$ of fluoxetine, meeting DSM-IV criteria for dependence. ${ }^{85}$ SSRIs are thought to be relatively safe in overdose; relatively rare fatalities have involved coingestion of alcohol or drugs dependent on the cytochrome P450 2D6 system, such as TCAs. ${ }^{91}$

\section{Tianeptine}

Tianeptine is an antidepressant manufactured and marketed in France but is not approved by the FDA or available in the USA. It is often classified as a TCA but is pharmacologically distinct. While its mechanism of action is not entirely clear, it is thought to be a serotonin enhancer and thus paradoxically acting in a manner opposite to that of the SSRIs, yet both have efficacy in depression. ${ }^{55,92-94}$ Tianeptine has been 
shown in rats to increase extracellular concentrations of dopamine in the nucleus accumbens, ${ }^{95}$ which may play a role in its abuse potential. There are a few case reports of tianeptine abuse in individuals seeking a "psychostimulant effect", using doses over 1,000 mg per day (usual maximum daily dose is $50 \mathrm{mg}$ ), and experiencing withdrawal phenomena. ${ }^{96-102}$ The route of abuse was not specified in the aforementioned cases but implied to be orally, with the exception of a case described by İlhan et al in which the individual began abusing tianeptine orally, but later began dissolving the tablets in water and administering the drug through intra-arterial puncture. ${ }^{102}$

\section{Amineptine}

Amineptine is another antidepressant classified as a tricyclic but is chemically different due to its 7-aminoheptanoic acid side chain; it has the unique capacity to reduce dopamine uptake selectively in vitro and in vivo. ${ }^{103,104}$ Amineptine was introduced to the market in France in 1978. There have been a number of case reports regarding abuse of amineptine, particularly in those with a history of substance abuse, attributed largely to its stimulant effect. ${ }^{105-115}$ According to the World Health Organization (WHO) reports of adverse drug reactions collected by the international drug monitoring program indicated a larger number of case reports of abuse and dependence for amineptine than for other schedule 4 stimulants. ${ }^{112}$ Amineptine was removed from the market in France and a number of other countries due to concerns regarding both hepatotoxicity and abuse. ${ }^{112}$ Its medical use, as well as abuse, in developing countries continues. ${ }^{112}$ Amineptine was never approved by the FDA and is not available in the USA.

We found no cases in the literature of abuse or misuse of serotonin 2 (5-HT2) receptor antagonists (trazodone and nefazodone) or mirtazapine (an alpha-2 adrenergic receptor blocker).

\section{Screening and evaluation: identifying prescription medication misuse}

As previously noted, the co-occurrence of mood and substance use disorders is common. ${ }^{18,19}$ While a detailed discussion of the complexity of diagnosis and treatment of individuals with such comorbidities is outside the scope of this discussion, it is important to note that the effect of treating depression in substance-dependent individuals is generally to improve depressive symptoms, but has limited impact on substance abuse outcomes. ${ }^{116,117}$ When evaluating an individual with depression, it is important to complete a careful assessment of substance use, including misuse of prescription medications. Individuals may present with depressive symptoms that may in fact be "substance-induced", a distinction that would have important implications for diagnosis, treatment, and prognosis. ${ }^{118,119}$ Further, identification of a concurrent substance use disorder should inform the recommended pharmacologic management of the mood disorder and has important implications for treatment decisions ${ }^{118,120,121}$ (see Table 2).

Similar to the strategy recommended for minimizing prescription opioid misuse, a "universal precautions" approach is most likely to identify patients at heightened risk for antidepressant abuse or misuse. ${ }^{122,123}$ A number of screening instruments are available for the identification of at-risk substance use and misuse. The Screening, Brief Intervention, and Referral to Treatment is a comprehensive, integrated, public health approach to the delivery of early intervention for individuals with risky alcohol and drug use, and timely referral for more intensive substance abuse

Table 2 Clinical tools and principles for minimizing risk of antidepressant misuse

\begin{tabular}{lll}
\hline $\begin{array}{l}\text { Method of } \\
\text { ascertainment }\end{array}$ & Example & Principle \\
\hline Clinical interviews & $\begin{array}{l}\text { Obtain history of illicit substance and alcohol abuse } \\
\text { Obtain history of antidepressant and other prescription } \\
\text { medication misuse } \\
\text { Ask about family history of substance abuse } \\
\text { Consider motivation for misuse }\end{array}$ & $\begin{array}{l}\text { Universal precautions reduce stigma and } \\
\text { improve care }\end{array}$ \\
Objective instruments & $\begin{array}{l}\text { Screening tools (eg, Screening, Brief Intervention, and Referral } \\
\text { to Treatment }\end{array}$ & Uniform approach to baseline risk assessment \\
Ongoing monitoring & $\begin{array}{l}\text { Urine toxicology, serum drug levels, frequent appointments, } \\
\text { monitor for aberrant behaviors (eg, early refill requests, erratic }\end{array}$ & Combining objective data with clinical \\
appointment attendance, indifference to side effects) & observation is more effective at minimizing risk
\end{tabular}


treatment for those who have substance abuse disorders. ${ }^{124}$ Risky use of prescription medications is defined by the National Center on Addiction and Substance Abuse at Columbia University as using a prescription drug not as prescribed or for other nonmedical reasons (eg, intoxicating effects, getting high). ${ }^{125}$ Once an individual's use is identified as "risky", the next step is to determine if he/she meets criteria for a substance use disorder. Symptoms of a "use disorder" as defined by the DSM-V (Diagnostic and Statistical Manual of Mental Disorders, Fifth Edition) include a problematic use of the substance leading to clinically significant impairment or distress, as manifested by at least two of the following in a 12-month period: taking the substance in larger amounts or over a longer period than was intended; persistent desire to cut down or control use; spending a great deal of time using or recovering from the effects of the drug; craving or a strong desire or urge to use the drug; recurrent use resulting in failure to fulfill a major role obligation at work, school, or home; continued use despite persistent social or interpersonal problems caused or exacerbated by the drug use; important social, occupational, or recreational activities are given up or reduced because of the drug use; recurrent use in physically hazardous situations; use despite having a persistent physical or psychological problem that is caused or exacerbated by the drug; tolerance; and withdrawal. ${ }^{126}$

A key component of the Screening, Brief Intervention, and Referral to Treatment is linking the screening results with appropriate early intervention services or referral to treatment. ${ }^{127}$ If an individual meets criteria for a "use disorder", he or she would benefit from referral to an addiction specialist, or at the least, the treating physician should consult an addiction expert. If the individual is identified as having "risky use", but not a "use disorder", then a brief intervention may be appropriate. Brief interventions focus on motivating clients to change their substance use. ${ }^{124,127}$ Screening and brief interventions have been found to be effective in reducing alcohol use (decreased heavy drinking episodes, decreased weekly alcohol consumption, and increased rates of adherence to recommended drinking limits); ${ }^{128-130}$ the United States Preventative Services Task Force recommends clinicians screen adults aged 18 years of age and older for alcohol misuse. ${ }^{129}$ The results for screening and brief interventions for illicit drug use, however, have been inconsistent or have shown short-term, small effects. ${ }^{131-133}$ The United States Preventative Services Task Force has not recommended screening and brief interventions for illicit drug use due to inadequate evidence to recommend for or against it, noting that much of the data regarding treatment interventions have come from treatment-seeking populations, and the generalizability of these findings to general primary care populations may be limited. ${ }^{134}$ There are no available data specific to antidepressant misuse.

The signs of antidepressant misuse can be difficult to identify. Patients engaged in nonmedical use of a prescribed medication are typically motivated to conceal this behavior from the prescribing physician. However, the presence of aberrant behaviors can alert the clinician to an increased likelihood of prescription medication abuse. Such behaviors may include erratic ability to keep appointments, requests for early refills, a sudden request for dose increase in a patient with a previously stable mood on a lower dose of the antidepressant, an indifference to side effects, and a general decline in functioning. The presence of such behaviors should raise a "red flag" for the prescriber, and the clinical recommendation would be to treat the patient as being at higher risk for antidepressant, other medication, or other drug abuse.

Clinical research on abuse of another class of abuse medications, namely prescription opioids, has revealed that monitoring for both urine toxicology and aberrant behaviors is more likely to detect patients engaging in prescription misuse than is monitoring either alone. ${ }^{135}$ Thus, implementing urine toxicology testing for patients suspected of antidepressant misuse will help to identify occult substance abuse issues that may require concurrent treatment or referral to an addiction specialist.

\section{Management of depression in patients misusing antidepressants}

Taking a careful history and risk stratification assessment, including a history of legal, prescribed, and illicit drug abuse, is an important strategy for reducing the likelihood of antidepressant misuse when evaluating a new patient. However, in some cases, unsuspected antidepressant abuse will be detected once treatment has begun. If misuse of an antidepressant is identified, it is important for the provider to take an open, nonjudgmental approach. From a clinical perspective, it is crucial to understand what is motivating the patient's antidepressant misuse. For example, the incarcerated cocaine-dependent individual using bupropion as a cocaine replacement to get "high" is a very different scenario from the depressed individual with ongoing insomnia who is misusing his/her TCA to enhance sedative properties. The former would warrant treatment by an addiction specialist; the latter likely would not. Understanding the reasons for misuse also allows for the potential opportunity to more accu- 
rately address any ongoing or untreated psychiatric symptoms that the patient may be attempting to "self-medicate".

With respect to available treatment options for the patient who has been discovered to be engaging in antidepressant abuse, the physician may choose to continue treatment using a medication with different pharmacologic properties from the drug which the patient has misused. When antidepressant misuse is identified, it is also essential to determine how much the individual is using and route of administration (ie, oral, intranasal, intravenous, rectal). This information is important to obtain, as it allows for assessment of risk; each of the antidepressants comes with its own profile of side effects, overdose risk, and lethality. Patients should be triaged based upon degree of medical risk and may warrant immediate consultation with a local poison control center, referral to an emergency department or urgent care center, referral to a primary doctor for evaluation, or further medical work-up (eg, obtain tricyclic levels, electrocardiography). It is also important to understand how the patient perceives his or her misuse of the antidepressant (eg, the medication provides relief from subjective states of distress that should be a focus of treatment) and the potential medical consequences of misuse. This information will allow for psychoeducation about specific risks, and also provide insight into the degree of motivation to change.

There is a paucity of evidence-based research to guide the pharmacologic management of individuals with comorbid mood and substance use disorders, ${ }^{120}$ and there are no existing treatment guidelines for the depressed individual who is also misusing antidepressants. Knowledge about a patient's reasons for misuse may assist the physician in choosing an antidepressant with pharmacologic properties that might better address ongoing symptomatology, or one with a lower abuse liability for that particular patient. Unlike other substances of abuse, antidepressants are not included in standard drug screen panels. Serum levels of all antidepressants can, however, be tested and potentially used for detection. However, only tricyclic antidepressant levels are used clinically and have defined reference ranges, limiting the interpretability of the results of the other antidepressant classes. Urine tests of tricyclic antidepressants are often used in emergency departments in cases of suspected overdose, and in the pain literature for pain management compliance testing. ${ }^{136-139}$ Qualitative urine tests of SSRIs, SNRIs, and bupropion exist, and a number of different methods of detection have been proposed and studied, but to date these tests are not used clinically, and the commercial availability of such tests appears limited. ${ }^{140-145}$
In contrast with the state-run prescription monitoring programs that provide an electronic database to prevent abuse of controlled medications, no such database currently exists for noncontrolled substances. However, contact with the patient's pharmacy (with the patient's permission) to identify other prescriptions he/she has filled may provide another means of monitoring. Such efforts may or may not detect misuse in those receiving prescriptions from friends or family, or if filling prescriptions at multiple pharmacies. Frequent appointments with the patient and prescribing in smaller amounts (eg, 2 weeks' supply at a time) and without refills, may also be helpful in the treatment of an individual with known antidepressant misuse.

The majority of patients will not achieve full remission from depression with an initial antidepressant treatment. ${ }^{146}$ Alternatives include switching to an alternative medication, adding a natural product such as 1-methylfolate or s-adenosylmethionine, or adding cognitive-behavioral psychotherapy. ${ }^{146}$ In addition to pharmacotherapy, psychotherapeutic strategies effective as first-line treatments include interpersonal psychotherapy and cognitive-behavioral therapy. ${ }^{147}$ Cognitive-behavioral therapy has also been found to be an effective adjunct to usual care, including antidepressant treatment. ${ }^{148}$ Other nonpharmacologic modalities that have shown therapeutic efficacy in depression include electroconvulsive therapy and magnetic seizure therapy. Preliminary research suggests that the latter exerts antidepressant activity in the absence of cognitive side effects. ${ }^{149}$ Mindfulness-based cognitive therapy has also been found to reduce mood and anxiety symptoms of depression ${ }^{150}$ and to lower the risk of relapse to, or recurrence of, major depression. ${ }^{151}$

For patients with substance use disorders co-occurring with depression, integrated treatment delivered in a group setting has been found to be more effective than treatment as usual. ${ }^{152}$ Integrated treatment for co-occurring disorders is associated with better treatment outcomes, but there is a wide range of approaches included in integrated treatment, including complementary and alternative therapies such as music and art therapy ${ }^{153}$ or acupuncture therapy. ${ }^{154}$ Another nonpharmacologic approach that has proven effective for depression is the use of exercise to augment an antidepressant regimen. ${ }^{155}$ Other alternative treatments for depression include yoga, tai chi, massage therapy, music therapy, and spirituality. ${ }^{156}$ Cognitive therapy has been found to be an effective strategy for depression, including treatmentresistant depression. ${ }^{157}$ The addition of cognitive-behavioral therapy has also been found to be cost-effective in patients who have not responded to antidepressants. ${ }^{158}$ 


\section{Summary and conclusion}

Nonmedical use of prescription drugs is an underrecognized clinical problem and is related to a number of factors, including increased access to medications and a perception that they are safer than illicit substances. There are, however, a number of potential negative medical and societal consequences of nonmedical use of prescription drugs. Further, while the majority of those using prescription medications nonmedically do not meet criteria for DSM-V substance use disorder, some individuals will develop such a disorder, and early nonmedical prescription drug use may be a predictor of lifetime development of prescription drug abuse or dependence. ${ }^{9}$

The scope of antidepressant misuse is unknown, as antidepressants are currently not included in the largescale epidemiologic surveys of prescription drug misuse. However, while antidepressants are generally thought to have low abuse liability, there is evidence in the literature of their misuse, abuse, and dependence. The majority of reported cases of antidepressant abuse occur in individuals with comorbid substance use and mood disorders. The most common motivation for abuse, across all classes of antidepressants, is to achieve a psychostimulant-like effect, including a desire for a "high" or euphoria. While it is important to recognize that the vast majority of individuals prescribed antidepressants do not misuse them, it is also critical for physicians to be aware of the potential for misuse and abuse when prescribing these drugs. Vulnerable populations include those with a current or past history of substance abuse and those in controlled environments. Warning signs include the presence of aberrant behaviors. Even in the absence of such behaviors, physicians should consider including antidepressants when screening for current and past risky prescription medication use.

When risky use or misuse of antidepressants is identified, the prescriber should explore the pattern of use, including the patient's motivation to misuse. It is important to differentiate the misuse of antidepressants to relieve psychological distress (eg, unauthorized dose escalation to reduce anxiety, achieve sleep, or combat fatigue) from abuse with the purpose of seeking euphoria. The former is likely to respond to patient psychoeducation and improved symptom control, whereas the latter may require more intensive clinical interventions, including concurrent substance abuse treatment or referral to an addiction expert.

While it is necessary for prescribers to be aware that antidepressants carry some abuse liability, physicians should not withhold essential pharmacotherapy, even in those with substance dependence. Several classes of antidepressants have demonstrated efficacy in improving depressive symptoms, and these drugs significantly reduce the mortality and morbidity in those suffering from depression. Additionally, misuse of an antidepressant is not necessarily a reason to withdraw antidepressant treatment. However, when misuse is identified, a thoughtful treatment approach should include patient education, maximizing psychotherapy, considering a different antidepressant class, augmenting with behavioral and alternative strategies (eg, exercise), close monitoring, and ongoing consideration of referral to an addiction specialist.

Future research efforts should be directed at collecting epidemiologic data regarding antidepressant misuse to better appreciate the scope of this clinical problem. It will be important to develop better tools for detecting antidepressant misuse, to better characterize risk factors, as well as to gain further insight into specific pharmacologic properties that contribute to abuse liability. Risk stratification screening tools and affordable urine and/or serum toxicology testing should continue to be developed as a means to identify and monitor medication misuse. Finally, future research should examine the course and consequences of antidepressant misuse, with a focus on improving early detection and developing effective treatment interventions.

\section{Disclosure}

The authors report no conflicts of interest in this work.

\section{References}

1. Centers for Disease Control and Prevention. Prescription drug overdoses: an American epidemic. Available from: http://www. cdc.gov/cdcgrandrounds/archives/2011/01-february.htm. Accessed June 15, 2014.

2. Huang B, Dawson DA, Stinson FS, et al. Prevalence, correlates, and comorbidity of nonmedical prescription drug use and drug use disorders in the United States: Results of the National Epidemiologic Survey on Alcohol and Related Conditions. J Clin Psychiatry. 2006;67: 1062-1107.

3. Hernandez SH, Nelson LS. Prescription drug abuse: insight into the epidemic. Clin Pharmacol Ther. 2010;88:307-317.

4. Substance Abuse and Mental Health Services Administration. Results from the 2012 National Survey on Drug Use and Health: summary of national findings. NSDUH Series H-46, HHS Publication No (SMA) 13-4795. Rockville, MD: Substance Abuse and Mental Health Services Administration; 2013. Available from: http://www.samhsa. gov/data/NSDUH/2012SummNatFindDetTables/NationalFindings/ NSDUHresults2012.htm. Accessed June 15, 2014.

5. Manubay JM, Muchow C, Sullivan MA. Prescription drug abuse: epidemiology, regulatory issues, chronic pain management with narcotic analgesics. Prim Care. 2011;38:71-90.

6. Bettinardi-Angres K, Bickelhaupt E, Bologeorges S. Non-medical use of prescription drugs: implications for NPs. Nurse Pract. 2012;37: 39-45.

7. Forman RF, Marlowe DB, McLellan AT. The Internet as a source of drugs of abuse. Curr Psychiatry Rep. 2006;8:377-382. 
8. National Center on Addiction and Substance Abuse at Columbia University 'You've got drugs!', IV: prescription drug pushers on the Internet. A CASA white paper. 2007. Available from: http://www.casacolumbia. org/addiction-research/reports/youve-got-drugs-perscription-drugpushers-internet-2008. Accessed June 15, 2014.

9. McCabe SE. Misperceptions of non-medical prescription drug use: a web survey of college students. Addict Behav. 2008;33:713-714.

10. Johnston LD, O’Malley PM, Miech RA, Bachman JG, Schulenberg JE. Monitoring the future national results on drug use: 1975-2013: overview, key findings on adolescent drug use. Ann Arbor, MI, USA: Institute for Social Research, The University of Michigan; 2014. Available from: http://www.monitoringthefuture.org/pubs/monographs/ mtf-overview2013.pdf. Accessed June 15, 2014.

11. Metlife Foundation. The Partnership at Drugfree Org. 2012 Partnership Attitude Tracking Study. Available from: http://www.drugfree.org/wpcontent/uploads/2013/04/PATS-2012-FULL-REPORT2.pdf. Accessed June 15, 2014.

12. Substance Abuse and Mental Health Services Administration, Drug Abuse Warning Network, 2011: National Estimates of Drug-Related Emergency Department Visits. HHS Publication No (SMA) 13-4760, DAWN Series D-39. Rockville, MD: Substance Abuse and Mental Health Services Administration, 2013. Available from: http://www.samhsa.gov/data/2k13/ DAWN2k11ED/DAWN2k11ED.htm. Accessed June 15, 2014.

13. Mack KA; Centers for Disease Control and Prevention. Drug-induced deaths - United States, 1999-2010. MMWR Surveill Summ. 2013; 62 Suppl 3:161-163.

14. Jones CM, Mack KA, Paulozzi LJ. Pharmaceutical overdose deaths, United States, 2010. JAMA. 2013;309:657-659.

15. McCabe SE, West BT, Morales M, Cranford JA, Boyd CJ. Does early onset of non-medical use of prescription drugs predict subsequent prescription drug abuse and dependence? Results from a national study. Addiction. 2007;102:1920-1930.

16. Birnbaum HG, White AG, Schiller M, Waldman T, Cleveland JM, Roland CL. Societal costs of prescription opioid abuse, dependence, and misuse in the United States. Pain Med. 2011;12:657-667.

17. Hansen RN, Oster G, Edelsberg J, Woody GE, Sullivan SD. Economic costs of nonmedical use of prescription opioids. Clin J Pain. 2011;27:194-202.

18. Hasin DS, Goodwin RD, Stinson FS, Grant BF. Epidemiology of major depressive disorder: results from the National Epidemiologic Survey on Alcoholism and Related Conditions. Arch Gen Psychiatry. 2005;62:1097-1106.

19. Merikangas KR, Akiskal HS, Angst J, et al. Lifetime and 12-month prevalence of bipolar spectrum disorder in the National Comorbidity Survey replication. Arch Gen Psychiatry. 2007;64:543-552.

20. Baumbacher G, Hansen MS. Abuse of monoamine oxidase inhibitors. Am J Drug Alcohol Abuse. 1992;18:399-406.

21. Eyer F, Jetzinger E, Pfab R, Zilker T. Withdrawal from high-dose tranylcypromine. Clin Toxicol (Phila). 2008;46:261-263.

22. Chatterjee A, Tosyali MC. Thrombocytopenia and delirium associated with tranylcypromine overdose. J Clin Psychopharmacol. 1995;15:143-144.

23. Davids E, Röschke J, Klawe C, Gründer G, Schmoldt A. Tranylcypromine abuse associated with delirium and thrombocytopenia. J Clin Psychopharmacol. 2000;20:270-271.

24. Antosik-Wojcinska AZ, Bzinkowska D, Chojnacka M, Swiecicki L, Torbinski J. ["Addiction" to phenelezine-case report]. Psychiatr Pol. 2013;47:127-134. Polish.

25. Mielczarek J, Johnson J. Tranylcypromine (letter). Lancet. 1963;1: 388-389.

26. Le Gassicke J. Tranylcypromine. Lancet. 1963;1:269-270.

27. Shopsin B, Kline NS. Monoamine oxidase inhibitors: potential for drug abuse. Biol Psychiatry. 1976;11:451-456.

28. Ben-Arie O, George G. A case of tranylcypromine (Parnate) addiction. Br J Psychiatry. 1979;135:273-274.

29. Westermeyer J. Addiction to tranylcypromine (Parnate): a case report. Am J Drug Alcohol Abuse. 1989;15:345-350.
30. Briggs NC, Jefferson JW, Koenecke FH. Tranylcypromine addiction: a case report and review. J Clin Psychiatry. 1990;51:426-429.

31. Brady KT, Lydiard RB, Kellner C. Tranylcypromine abuse (letter). Am J Psychiatry. 1991;148:1268-1269.

32. Griffin N, Draper RJ, Webb MJ. Addiction to tranyclcypromine. BMJ 1981;283:346.

33. Szeleyni A, Albrecht J. Tranylcypromine abuse associated with an isolated thrombocytopenia. Pharmacopsychiatry. 1998;31:238-240.

34. Vartzopoulos D, Krull F. Dependence on monoamine oxidase inhibitors in high dose. Br J Psychiatry. 1991;158:856-857.

35. Gahr M, Schönfeldt-Lecuona C, Kölle MA, Freudenmann RW. Withdrawal and discontinuation phenomena associated with tranylcypromine: a systematic review. Pharmacopsychiatry. 2013;46:123-129.

36. Haddad P. Do antidepressants have any potential to cause addiction? J Psychopharmacol. 1999;13:300-307.

37. García-Campayo JJ, Sanz-Carrillo C, Ferrández Payo M. [Abuse of the monoamine oxidase (MAOI) inhibitors as antidepressive drugs: a critical review]. Actas Luso Esp Neurol Psiquiatr Cienc Afines. 1995;23:217-222. Spanish.

38. Phillips D. Wellbutrin: misuse and abuse by incarcerated individuals. J Addict Nurs. 2012;23:65-69.

39. Hilliard WT, Barloon L, Farley P, Penn JV, Koranek A. Bupropion diversion and misuse in the correctional facility. J Correct Health Care. 2013;19:211-217.

40. Reeves RR, Ladner ME. Additional evidence of the abuse potential of bupropion. J Clin Psychopharmacol. 2013;33:584-585.

41. Yoon G, Westermeyer J. Intranasal bupropion abuse: a case report. Am $J$ Addict. 2013;22:180.

42. Vento AE, Schifano F, Gentili F, et al. Bupropion perceived as a stimulant by two patients with a previous history of cocaine misuse. Ann Ist Super Sanita. 2013;49:402-405.

43. Baribeau D, Araki KF. Intravenous bupropion: a previously undocumented method of abuse of a commonly prescribed antidepressant agent. J Addict Med. 2013;7:216-217.

44. McCormick J. Recreational bupropion abuse in a teenager. Br J Clin Pharmacol. 2002;53:214.

45. Del Paggio D. Psychotropic medication abuse in correctional facilities. Bay Area Psychopharmacology Newsletter. 2005;8:1-6.

46. Kim D, Steinhart B. Seizures induced by recreational abuse of bupropion tablets via nasal insufflation. CJEM. 2010;12:158-161.

47. Hill S, Sikand H, Lee J. A case report of seizures induced by bupropion nasal insufflation. Prim Care Companion J Clin Psychiatry. 2007;9:67-69.

48. Khurshid KA, Decker DH. Bupropion insufflation in a teenager. J Child Adolesc Psychopharmacol. 2004;14:157-158.

49. Welsh CJ, Doyon S. Seizure induced by insufflations of bupropion. N Engl J Med. 2002;347:951.

50. Langguth B, Hajak G, Landgrebe M, Unglaub W. Abuse potential of bupropion nasal insufflation: a case report. J Clin Psychopharmacol. 2009;29:618-619.

51. Stahl SM, Pradko JF, Haight BR, Modell JG, Rockett CB, LearnedCoughlin S. A review of the neuropharmacology of bupropion, a dual norepinephrine and dopamine reuptake inhibitor. Prim Care Companion J Clin Psychiatry. 2004;6:159-166.

52. Nomikos GG, Damsma G, Wenkstern D, Fibiger HC. Acute effects of bupropion on extracellular dopamine concentrations in rat striatum and nucleus accumbens studied by in vivo microdialysis. Neuropsychopharmacology. 1989;2:273-279.

53. Davidson JR, Connor KM. Bupropion sustained release: a therapeutic overview. J Clin Psychiatry. 1998;59 Suppl 4:25-31.

54. Koob GF. Neurobiology of addiction. In: Galanter M, Kleber HD, editors. Textbook of Substance Abuse Treatment. 4th ed. Arlington, VA, USA: American Psychiatric Publishing Inc; 2008.

55. Stahl SM. Stahl's Essential Psychopharmacology. The Prescriber's Guide. 4th ed. New York, NY, USA: Cambridge University Press; 2011.

56. Rettew DC, Hudziak JJ. Bupropion. In: Schatzberg AF, Nemeroff CB, editors. Essentials of Clinical Psychopharmacology. 2nd ed. Arlington, VA, USA: American Psychiatric Publishing Inc; 2006. 
57. Machnik M, Sigmund G, Koch A, Thevis M, Schanzer W. Prevalence of antidepressants and biosimilars in elite sport. Drug test. Analysis. 2009;1:286-291.

58. World Anti-Doping Agency. The 2014 Monitoring Program. Available from: http://www.wada-ama.org/Documents/World_Anti-Doping_ Program/WADP-Prohibited-list/2014/WADA-Monitoring-Program2014-EN.pdf. Accessed June 16, 2014.

59. Schatzberg AF, Cole JO, DeBattista C. Manual of Clinical Psychopharmacology. 6th ed. Arlington, VA, USA: American Psychiatric Publishing Inc; 2007.

60. Druteika D, Zed PJ. Cardiotoxicity following bupropion overdose. Ann Pharmacother. 2002;36:1791-1795.

61. Krishnan KR. Monoamine oxidase inhibitors. In: Schatzberg AF, Nemeroff CB. Essentials of Clinical Psychopharmacology. 2nd ed. Arlington, VA, USA: American Psychiatric Publishing Inc; 2007.

62. Pennings EJ, Verkes RJ, de Koning J, Bommelé JJ, Jansen GS, Vermeij P. Tranylcypromine intoxication with malignant hyperthermia, delirium, and thrombocytopenia. J Clin Psychopharmacol. 1997;17:430-432.

63. Absher JR, Black DW. Tranylcypromine withdrawal delirium. J Clin Psychopharmacol. 1988;8:379-380.

64. Nelson JC. Tricyclic and tetracyclic drugs. In: Schatzberg AF, Nemeroff CB. Essentials of Clinical Psychopharmacology. 2nd ed. Arlington, VA, USA: American Psychiatric Publishing Inc; 2006.

65. Cohen MJ, Hanbury R, Stimmel B. Abuse of amitriptyline. JAMA. 1978;(13)240:1372-1373.

66. Baniewicz K. [Case of amitriptyline abuse]. Psychiatr Pol. 1978;12: 527-528. Polish

67. Vasiliades J. Identification of misused drugs in the clinical laboratory. Clin Biochem. 1980;13:24-29.

68. Delisle JD. A case of amitriptyline abuse. Am J Psychiatry. 1990;147:1377-1378.

69. Wohlreich MM. Amitriptyline abuse presenting as acute toxicity. Psychosomatics. 1993;34:191-193.

70. Dorman A, Talbot D, Byrne P, O'Connor J. Misuse of dothiepin. BMJ. 1995;311:1502.

71. Hepburn S, Harden J, Grieve JH, Hiscox J. Deliberate misuse of tricyclic antidepressants by intravenous drug users - case studies and report. Scott Med J. 2005;50:131-133.

72. Prahlow JA, Landrum JE. Amitriptyline abuse and misuse. $A m J$ Forensic Med Pathol. 2005;26:86-88.

73. Peles E, Schreiber S, Adelson M. Tricyclic antidepressant abuse, with or without benzodiazepine abuse, in former heroin addicts currently in methadone maintenance treatment (MMT). Eur Neuropsychopharmacol. 2008; 18:188-193.

74. Anand JS, Habrat B, Sut M, Korolkiewicz R. [Misuse of substances theoretically without abuse potential - case series]. Przegl Lek. 2009;66:290-292. Polish.

75. Shenouda R, Desan PH. Abuse of tricyclic antidepressant drugs. A case series. J Clin Psychopharmacol. 2013;33:440-441.

76. Richelson E. Tricyclic antidepressants and histamine H1 receptors. Mayo Clin Proc. 1979;54:669-674.

77. Thase ME, Sloan DME. Venlafaxine. In: Schatzberg AF, Nemeroff CB. Essentials of Clinical Psychopharmacology. 2nd ed. Arlington, VA, USA: American Psychiatric Publishing Inc; 2006.

78. Quaglio G, Schifano F, Lugoboni F. Venlafaxine dependence in a patient with a history of alcohol and amineptine misuse. Addiction. 2008;103:1572-1574.

79. Sattar SP, Grant KM, Bhatia SC. A case of venlafaxine abuse. $N$ Engl J Med. 2003;348:764-765.

80. Whyte IM, Dawsone AH, Buckley NA. Relative toxicity of venlafaxine and selective serotonin reuptake inhibitors in overdose compared to tricyclic antidepressants. QJM. 2003;99:369-374.

81. Parsons AT, Anthony RM, Meeker JE. Two fatal cases of venlafaxine poisoning. J Anal Toxicol. 1996;20:266-268.

82. Long C, Crifasi J, Maginn D, Graham M, Teas S. Comparison of analytical methods in the determination of two venlafaxine fatalities. $J$ Anal Toxicol. 1997;21:166-169.
83. Banham ND. Fatal venlafaxine overdose. Med J Aust. 1998;169: $445-448$.

84. Kunsman GW, Kunsman CM, Presses CL, Garavaglia JC, Farley NJ. A mixed-drug intoxication involving venlafaxine and verapamil. J Forensic Sci. 2000;45:926-928.

85. Taïeb O, Larroche C, Dutray B, Baubet T, Moro MR. Fluoxetine dependence in a former amineptine abuser. $\mathrm{Am} \mathrm{J}$ Addict. 2004;13:498-500.

86. Wilcox JA. Abuse of fluoxetine by a patient with anorexia nervosa. Am J Psychiatry. 1987;144:1100.

87. Pagliaro LA, Pagliaro AM. Fluoxetine abuse by an intravenous drug user. Am J Psychiatry. 1993;150:1898.

88. Tinsley JA, Olsen MW, Laroche RR, et al. Fluoxetine abuse. Mayo Clin Proc. 1994;69:166-168.

89. Menecier P, Menecier-Ossa L, Bern P. [Fluoxetine dependence and tolerance: a single case report]. Encephale. 1997;23:400-401. French.

90. Goldman MJ, Grinspoon L, Hunter-Jones S. Ritualistic use of fluoxetine by a former substance abuser. Am J Psychiatry. 1990;147:1377.

91. Dalfen AK, Stewart DE. Who develops severe or fatal adverse drug reactions to selective serotonin reuptake inhibitors? Can J Psychiatry. 2001;46:258-263.

92. Uzbekov MG. Antidepressant action of tianeptine is connected with acceleration of serotonin turnover in the synapse: a hypothesis. Neuropsychopharmacol Hung. 2009;11:83-87.

93. Kasper S, McEwen BS. Neurobiological and clinical effects of the antidepressant tianeptine. CNS Drugs. 2008;22:15-26.

94. Wilde MI, Benfield P. Tianeptine. A review of its pharmacodynamic and pharmacokinetic properties, and therapeutic efficacy in depression and coexisting anxiety and depression. Drugs. 1995;49:411-439.

95. Invernizzi R, Pozzi L, Garattini S, Samanin R. Tianeptine increases the extracellular concentrations of dopamine in the nucleus accumbens by a serotonin-independent mechanism. Neuropharmacology. 1992;31:221-227.

96. Kisa C, Bulbul DO, Cigdem A, Goka E. Is it possible to be dependent to tianeptine, an antidepressant? A case reports. Prog Neuropsychopharmacol Biol Psychiatry. 2007;31:776-778.

97. Saatcioglu O, Erim R, Cakmak D. [A case of tianeptine abuse]. Turk Psikiyatri Derg. 2006;17:72-75. Turkish.

98. Vandel P, Regina W, Bonin B, Sechter D, Bizouard P. [Abuse of tianeptine. A case reports]. Encephale. 1999;25:672-673. French.

99. Guillem E, Lepine JP. [Does addiction to antidepressant exist? About a case of one addiction to tianeptine]. Encephale. 2003;29:456-459. French.

100. Vadachkoria D, Gabunia L, Gambashidze K, Pkhaladze N, Kuridze N. Addictive potential of tianeptine - the threatening reality. Georgian Med News. 2009;174:92-94.

101. Leterme L, Singlan YS, Auclair V, Le Boisselier R, Frimas V. [Misuse of tianeptine: five cases of abuse]. Ann Med Interne (Paris). 2003;154:S58-63. French.

102. İlhan, G, Ergene S, Durakoğlugil, T, Karamustafa H, Karakisi O, Bozok S. Bilateral pseudoaneurysm secondary to intraarterial tianeptine abuse. Anadolu Kardiyol Derg. 2013;13:814-815.

103. Garattini S, Mennini T. Pharmacology of amineptine: synthesis and updating. Clin Neuropharmacol. 1989;12 Suppl 2:S13-S18.

104. Garattini S. Pharmacology of amineptine, an antidepressant agent acting on the dopaminergic system: a review. Int Clin Psychopharmacol. 1997;12 Suppl 3:S15-S19.

105. Biondi F, Di Rubbo R, Faravelli C, Mannaioni PF. Chronic amineptine abuse. Biol Psychiatry. 1990;28:1004-1006.

106. Ginestet D, Cazas O, Branciard M. [Two cases of amineptine dependence]. Encephale. 1984;10:189-191. French.

107. Bertschy G, Luxembourger I, Bizouard P, Vandel S, Allers G, Volmat R. [Amineptine dependence. Detection of patients at risk. Report of eight cases]. Encephale. 1990;16:405-409. French.

108. Castot A, Benzaken C, Wagniart F, Efthymiou ML. [Analysis of 155 cases. An evaluation of the official cooperative survey of the Regional Centers of Pharmacovigilance]. Therapie. 1990;45:399-405. French. 
109. Duriot JF, Dutertre JP, Grenier JM, Autret A, Martin A. [Amineptine dependence and iatrogenic acne. Review of the literature apropos of a case]. Ann Med Psychol (Paris). 1991;149:795-797. French.

110. Prieto JM, Gost A, Obiols J, Caycedo N. Amineptine dependence and schizophrenia. Biol Psychiatry. 1994;36:266-268.

111. Bettoli V, Trimurti S, Lombardi AR, Virgili A. Acne due to amineptine abuse. J Eur Acad Dermatol Venereol. 1998;10:281-283.

112. WHO Expert Committee on Drug Dependence. World Health Organization Technical Series 915, 2003. Available from: http://whqlibdoc. who.int/trs/WHO_TRS_915.pdf?ua=1. Accessed June 16, 2015.

113. Perera I, Lim L. Amineptine and midazolam dependence. Singapore Med J. 1998;39:129-131.

114. Ahmed SH, Haq I. Amineptine dependence. J Pak Med Assoc. 1994;44:222-223.

115. Pérez de los Cobos JC, Jorda LL, Pelegrin C. [A case of amineptine dependence]. Encephale. 1990;16:41-42. French.

116. Nunes EV, Levin FR. Treatment of depression in patients with alcohol or other drug dependence. A meta-analysis. JAMA 2004;291:1887-1896.

117. Pettinati HM. Antidepressant treatment of co-occurring depression and alcohol dependence. Biol Psychiatry. 2004;56:785-792.

118. Schuckit MA. Comorbidity between substance use disorders and psychiatric conditions. Addiction. 2006;101 Suppl 1:76-88.

119. Volkow ND. The reality of comorbidity: depression and drug abuse. Biol Psychiatry. 2004;56:714-717.

120. Pettinati HM, O'Brien CP, Dundon WD. Current status of co-occurring mood and substance use disorders: a new therapeutic target. Am J Psychiatry. 2013;170:23-30.

121. Kelly TM, Daley DC, Douaihy AB. Treatment of substance abusing patients with comborbid psychiatric disorders. Addict Behav. 2012;37:11-24.

122. Gourlay DL, Heit HA. Universal precautions revisited: managing the inherited pain patient. Pain Med. 2009;10 Suppl 2:S115-S123.

123. Weaver MF, Schnoll SH. Opioid treatment of chronic pain in patients with addiction. J Pain Palliat Care Pharmacother. 2002;16:5-26.

124. Whitepaper on Screening, Brief Intervention and Referral to Treatment (SBIRT) in Behavioral Healthcare. 2011. http:/www.samhsa. gov/prevention/sbirt/SBIRTwhitepaper.pdf.

125. Casa Columbia. Overview of brief intervention for risky substance use in primary care. 2014. Available from: http://www.casacolumbia. org/sites/default/files/files/Overview-of-brief-intervention-for-riskysubstance-use-in-primary-care.pdf. Accessed June 15, 2014.

126. American Psychiatric Association. Diagnostic and Statistical Manual of Mental Disorders. 5th ed. Arlington, VA, USA: American Psychiatric Publishing Inc; 2013.

127. Babor TF, McRee BG, Kassebaum PA, Grimaldi PL, Ahmed K, Bray J. Screening, Brief Intervention, and Referral to Treatment (SBIRT): toward a public health approach to the management of substance abuse. Subst Abus. 2007;28:7-30.

128. Jonas DE, Garbutt JC, Amick HR, et al. Behavioral counseling after screening for alcohol misuse in primary care: a systematic review and meta-analysis for the U.S. Preventive Services Task Force. Ann Intern Med. 2012;157:645-654.

129. Moyer VA; Preventive Services Task Force. Screening and behavioral counseling interventions in primary care to reduce alcohol misuse: U.S. preventive services task force recommendation statement. Ann Intern Med. 2013;159:210-218.

130. O'Donnell A, Anderson P, Newbury-Birch D, et al. The impact of brief alcohol interventions in primary healthcare: a systematic review of reviews. Alcohol Alcohol. 2014;49:66-78.

131. Walton MA, Resko S, Barry KL, et al. A randomized controlled trial testing the efficacy of a brief cannabis universal prevention program among adolescents in primary care. Addiction. 2014;109:786-797.

132. Woodruff SI, Eisenberg K, McCabe CT, Clapp JD, Hohman M. Evaluation of California's alcohol and drug screening and brief intervention project for emergency department patients. West JEmerg Med. $2013 ; 14: 263-270$.
133. Humeniuk R, Ali R, Babor T, et al. A randomized controlled trial of a brief intervention for illicit drugs linked to the Alcohol, Smoking and Substance Involvement Screening Test (ASSIST) in clients recruited from primary health-care settings in four countries. Addiction. 2012;107: 957-966.

134. Polen MR, Whitlock EP, Wisdom JP, Nygren P, Bougatsos C. Screening in primary care settings for illicit drug use: staged systematic review for the united states preventive services task force. Rockville, MD, USA: Agency for Healthcare Research and Quality; 2008. Available from: http://www. ncbi.nlm.nih.gov/books/NBK33960/. Accessed June 16, 2014.

135. Katz NP, Sherburne S, Beach M, et al. Behavioral monitoring and urine toxicology testing in patients receiving long-term opioid therapy. Anesth Analg. 2003;97:1097-1102.

136. Lin CN, Nelson GJ, McMillin GA. Evaluation of the NexScreen and DrugCheck Waive RT urine drug detection cups. J Anal Toxicol. 2013;37:30-36

137. Poklis JL, Wolf CE, Goldstein A, Wolfe ML, H Poklis A. Detection and quantification of tricyclic antidepressants and other psychoactive drugs in urine by HPLC/MS/MS for pain management compliance testing. J Clin Lab Anal. 2012;26:286-294.

138. Moeller KE, Lee KC, Kissack JC. Urine drug screening: practical guide for clinicians. Mayo Clin Proc. 2008;83:66-76.

139. Melanson SEF, Lewandrowski EL, Griggs DA, Flood JG. Interpreting tricyclic antidepressant measurements in urine in an emergency department setting: comparison of two qualitative point-of-care urine tricyclic antidepressant drug immunoassays with quantitative serum chromatographic analysis. J Anal Toxicol. 2007;31:270-275.

140. Das RS, Agrawal YK. Spectrofluoremetric analysis of new-generation antidepressant drugs in pharmaceutical formulations, human urine, and plasma samples. Journal of Spectroscopy. 2012;27:59-71.

141. Ulu ST, Tuncel M. Determination of bupropion using liquid chromatography with fluorescence detection in pharmaceutical perpations, human plasma and human urine. J Chromatogr Sci. 2012;50:433-439.

142. Unceta N, Goicolea MA, Barrio JR. Analytical procedures for the determination of the selective serotonin reuptake inhibitor antidepressant citalopram and its metabolites. Biomed Chromatogr. 2011;25:238-257.

143. Berzas Nevado JJ, Villasenor Llerena MJ, Guiberteau Cabanillas C, Rodriguez Robledo V. Screening of citalopram, fluoxetine and their metabolites in human urine samples by gas chromatography-mass spectrometry. A global robustness/ruggedness study. J Chromatogr A . 2006;1123:130-133.

144. Salgado-Petinal C, Lama JP, Garcia-Jares C, Llompart M, Cela R. Rapid screening of selective re-uptake inhibitors in urine samples using solid-phase microextraction gas chromatography-mass spectrometry. Anal Bioanal Chem. 2005;382:1351-1359.

145. Samanidou VF, Kourti PV. Rapid HPLC method for the simultaneous monitoring of duloxetine, venlafaxine, fluoxetine and paroxetine in biofluids. Bioanalysis. 2009;1:905-917.

146. Preston TC, Shelton RC. Treatment resistant depression: strategies for primary care. Curr Psychiatry Rep. 2013;15:370.

147. Van Hees ML, Rotter T, Ellermann T, Evers SM. The effectiveness of individual interpersonal psychotherapy as a treatment for major depressive disorder in adult outpatients: a systematic review. $B M C$ Psychiatry. 2013;13:22.

148. Wiles N, Thomas L, et al. Cognitive behavioural therapy as an adjunct to pharmacotherapy for primary care based patients with treatment resistant depression: results of the CoBalT randomised controlled trial. Lancet, 2013;381:375-384.

149. Fitzgerald PB, Hoy KE, Herring SE, Clinton AM, Downey G, Daskalakis ZI. Pilot study of the clinical and cognitive effects of high-frequency magnetic seizure therapy in major depressive disorder. Depress Anxiety, 2013;30:129-136.

150. Marchand WR. Mindfulness-based stress reduction, mindfulnessbased cognitive therapy, and Zen meditation for depression, anxiety, pain, and psychological distress. J Psychiatr Pract. 2012;18: 233-252. 
151. Huijbers MJ, Spijker J, Donders AR, et al. Preventing relapse in recurrent depression using mindfulness-based cognitive therapy, antidepressant medication or the combination: trial design and protocol of the MOMENT study. BMC Psychiatry.2012;12:125.

152. Wüsthoff LE, Waal H, Gråwe RW. The effectiveness of integrated treatment in patients with substance use disorders co-occurring with anxiety and/or depression -a group randomized trial. BMC Psychiatry. 2014; $14: 678$

153. Ross S, Cidambi I, Dermatis H, Weinstein J, Ziedonis D, Roth S, Galanter M. Music therapy: a novel motivational approach for dually diagnosed patients. J Addict Dis. 2008;27:41-53.

154. Courbasson CM, de Sorkin AA, Dullerud B, Van Wyk L. Acupuncture treatment for women with concurrent substance use and anxiety/ depression: an effective alternative therapy? Fam Community Health, 2007;30:112-120.
155. Mura G, Moro MF, Patten SB, Carta MG. Exercise as an add-on strategy for the treatment of major depressive disorder: a systematic review. CNS Spectr. 2014;3:1-13.

156. Nyer M, Doorley J, Durham K, Yeung AS, Freeman MP, Mischoulon D. What is the role of alternative treatments in late-life depression? Psychiatr Clin North Am. 2013;36:577-596.

157. Carvalho AF, Berk M, Hyphantis TN, McIntyre RS. The integrative management of treatment-resistant depression: a comprehensive review and perspectives. Psychother Psychosom. 2014;83:70-88.

158. Hollinghurst S, Carroll FE, Abel A, et al. Cost-effectiveness of cognitive-behavioural therapy as an adjunct to pharmacotherapy for treatment-resistant depression in primary care: economic evaluation of the CoBalT Trial. Br J Psychiatry. 2014;204:69-76.

\section{Dovepress}

\section{Publish your work in this journal}

Substance Abuse and Rehabilitation is an international, peer-reviewed, open access journal publishing original research, case reports, editorials, reviews and commentaries on all areas of addiction and substance abuse and options for treatment and rehabilitation. The manuscript management system is completely online and includes a very quick and fair peer-review system. Visit http://www.dovepress.com/testimonials.php to read real quotes from published authors. 